\title{
0735 ANIMAL RELATED INJURIES IN DAIRY FARMS IN-DEPTH INTERVIEWS WITH FARMERS
}

C Lindahl*, P Lundqvist Correspondence: Department of Work Science, Business Economics and Environmental Psychology, SLU - Swedish University of Agricultural Sciences Box 88, SE-230 53 Alnarp, Sweden

10.1136/ip.2010.029215.735

Animal-related accidents are among the most common occupational injuries in agriculture. A majority of these animalrelated injuries are due to dairy cattle. Occupational injuries cause human suffering as well as economical losses for the affected person and family and for society. There are numerous causes to why these accidents occur, which makes accident prevention a very complex issue. In-depth research is needed to give valuable insights into this relatively unexplored area. The aim of the study is to explore the farmers own experiences, thoughts and perceptions of why animalrelated accidents happen and what strategies are needed to prevent future accidents. In-depth interviews with Swedish dairy farmers will be conducted. Dairy farms will be selected based on production system, geographical location and farmers' gender and age, to ensure a representative sample. The interviews will be carried out during the first half of year 2010. This study is the first part of a $\mathrm{PhD}$ project with focus on prevention of occupational accidents in dairy farming. The results will be used as a basis for developing new ideas on how to effectively prevent animal-related accidents in agriculture. 